Article

\title{
Simulation of a Hydraulic Load Sensing Proportional
} Valve

\author{
Kongratbai Sharipov ${ }^{1}$ and Sanjar Mirzaliev ${ }^{2, *}$ \\ 1 Turin Polytechnic University in Tashkent; k.sharipov@polito.uz \\ 2 Turin Polytechnic University in Tashkent ; s254169@studenti.polito.it \\ * Correspondence: s254169@studenti.polito.it; Tel.: +39 3913098278
}

\begin{abstract}
Nowadays energy saving is a topical issue due to increasing fuel costs and this aspect is amplified by more stringent emissions regulations that impact on vehicle development. A recent study conducted by the U.S. Department of Energy shows that about five percent of the U.S. energy consumption is transmitted by fluid power equipment. Nevertheless, this study also shows that the efficiency of fluid power averages 21 percent. This offers a huge opportunity to improve the current state-of-the-art of fluid power machines, in particular to improve the energy consumption of current applications. These facts dictate a continuous strive toward improvements and more efficient solutions: to accomplish this objective a strong reduction of hydraulic losses and better control strategies of the hydraulic systems are needed. In fluid power, there exist many techniques to reduce/recover energy losses of the conventional layouts, e.g. load sensing, electrohydraulic flow matching, independent metering, etc. One of the most efficient ways to analyze these different layouts and identify the best hydraulic solution is done through virtual simulations instead of prototyping, since the latter involves higher investment costs to deliver the product into the market. However, to build a fluid power machine virtual model, some problems arise relative to different aspects, for instance: loads on actuators (both linear and rotational) are not constant and pumps are driven by a real engine whose speed depends on required torque. Furthermore, it is important to achieve higher level of detail to simulate each component in the circuit: the greater detail, the better the machine behavior is portrayed, but it obviously entails heavy impact on simulation time and computational resources. Therefore, there is a need to create mathematical model of components and systems with sufficient level of detail to easily acquire all those phenomena necessary to correctly evaluate machine performance and make modifications to the fluid power component design. In this context, a hydraulic proportional valve PVG 32 by Danfoss is taken as an object of study, its performance is analyzed with suitable mathematical model and simulation is done to observe closeness of a model to the laboratory experiment.
\end{abstract}

Keywords: Amesim; pressure compensated proportional spool valve; PVG32; discharge coefficient.

\section{Introduction}

There are many fluid power machines in the industry. An example from material handling equipment is a forklift truck. Hydraulic circuit of it consists of load sensing variable displacement pump in the flow generation unit, a block of PVG32 valve in the control unit and number of actuators as users. As a single flow generation unit feeds different actuators to steer the wheels, lift the load and incline the forks, this paper focuses on a control valve PVG32 involved in fluid power transfer. 
An example of the load sensing pre-compensation technique is a block of PVG32 made by Danfoss. There is a PVB module for each user followed by inlet module PVP. Each PVB module comes with electro-hydraulic actuation PVE and manual drive PVM for safety. The flow rate controlled by each PVB is exclusively a function of the available command signal. In fact, the load-sensing PVG32 makes the flow independent of each user, while there is a variability of the load between users. Working principle of PVG32 is present in the manual of the valve [1] and Mirzaliev [2] studied the valve with different types of spools.

Cross section of the PVB module is seen in Figure 1. Flow passing through the local compensator LC feeds port A or B depending on the main spool MS position, which is controlled by the operator via PVE or PVM.

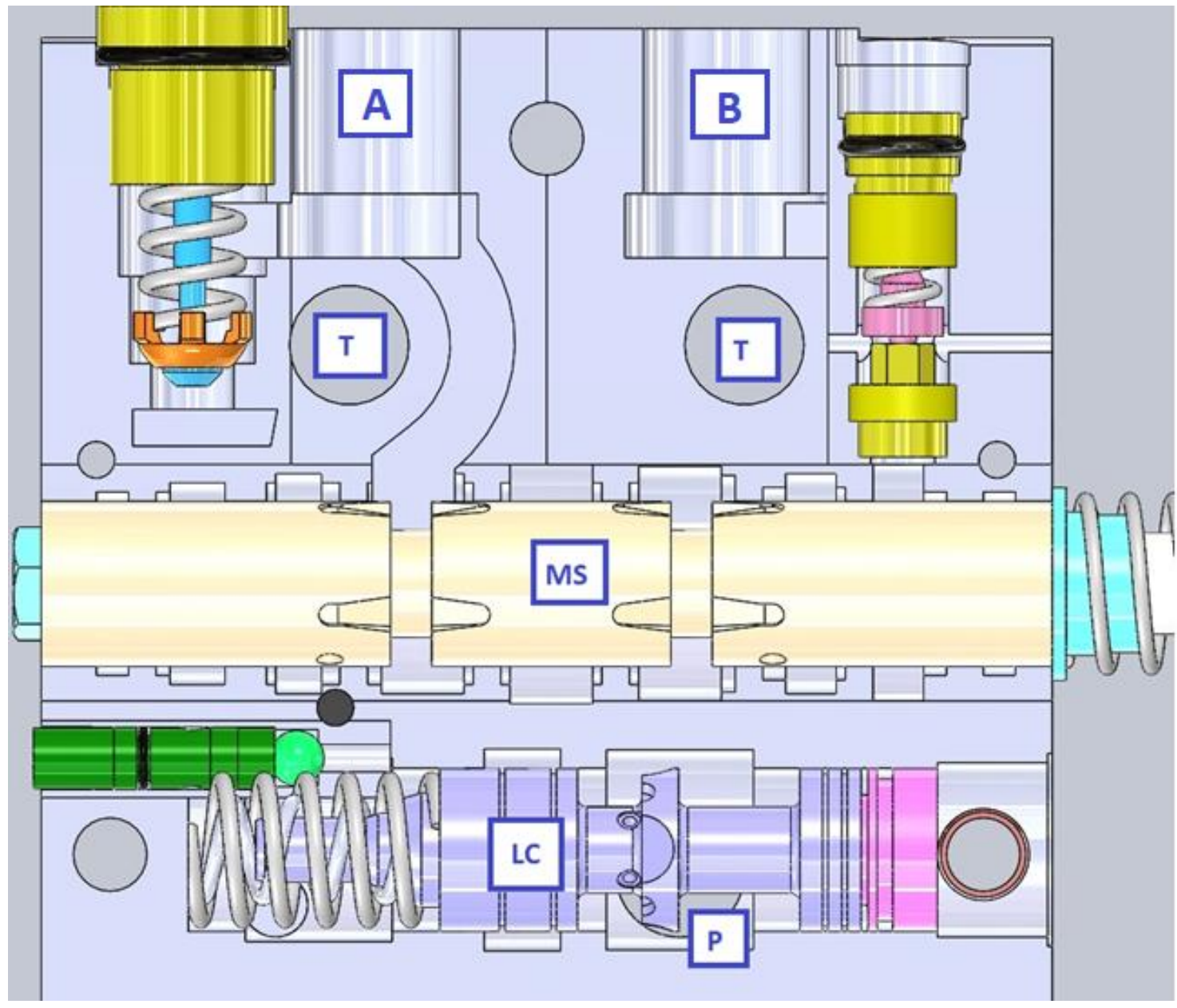

Figure 1. PVB cross section given in reference [4]

\section{Experimental tests}

Flow rate versus spool position. To start the steady state analysis of the block PVG32, it is possible to assume that local compensator is fixed in its regulating condition. By design, one can assume that its fixed position during regulation is such to have maximum opening and this position doesn't vary considerably at steady state operating condition. Therefore, in the experimental tests, the spacers are machined and mounted on the local compensator to fix its position in PVB block. As there are many configurations of the spool in the PVB module, such as floating center (serial no 9782) or closed center (serial no 9721), in the laboratory test, floating center spool is chosen. 
A B

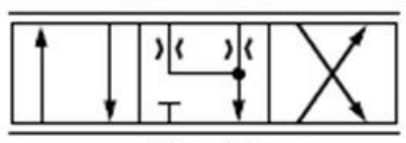

P $\quad \mathbf{T}$

\section{A B}

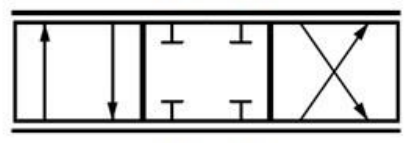

P $\quad \mathbf{T}$

Figure 2. ISO schemes of floating center (left) and closed center (right) spools

Experimental test on flow rate vs spool position is done by attaching an analog position sensor to the spool lever and measuring flow rate with a flow meter HM11(all data relevant to the experiment is seen in Appendix A). Data acquisition summary is seen in the Figure 2 below.

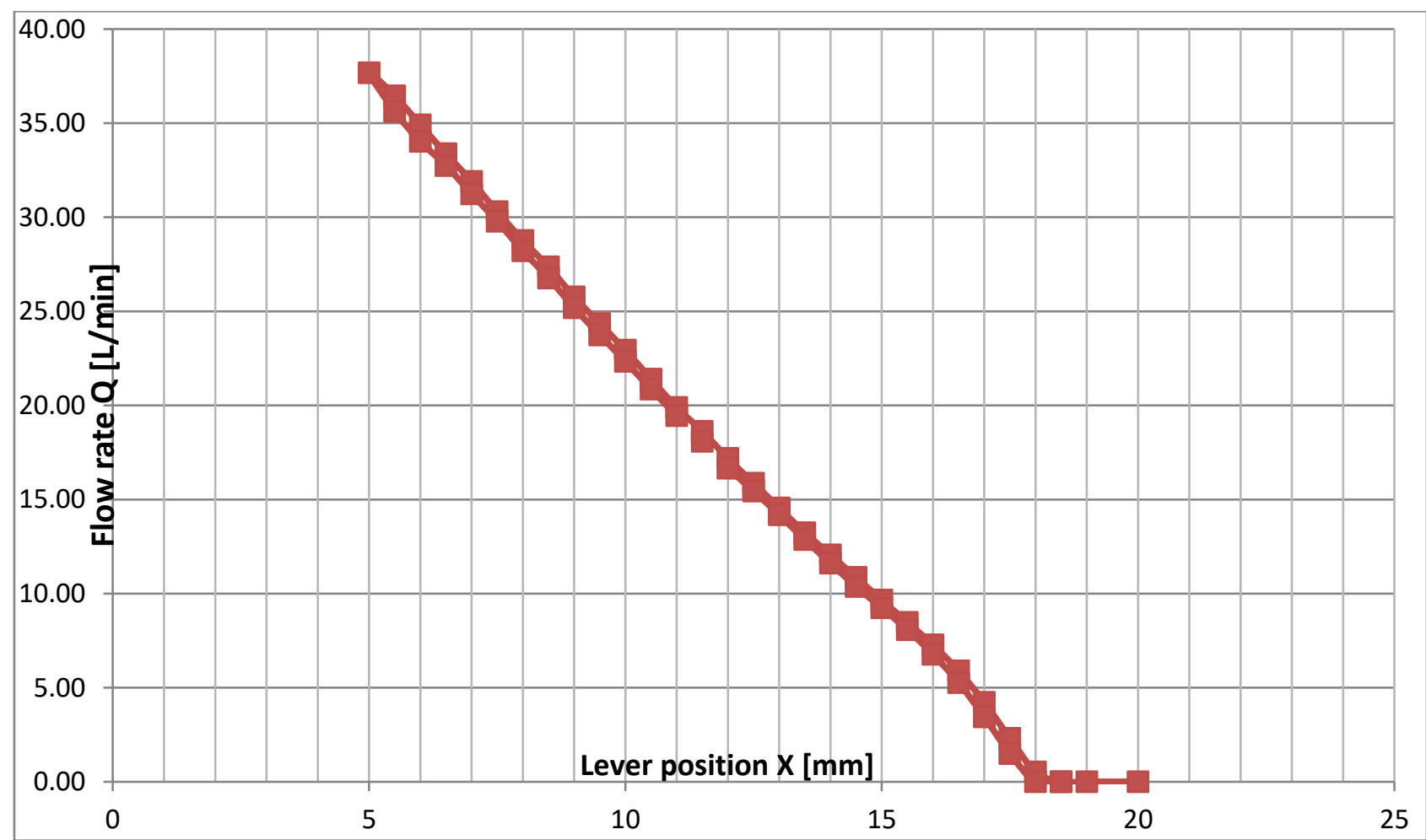

Figure 3. Summary of experimental test 1

Measured hysteresis is observed and the average values of the flow rate $Q$ are taken. It is sufficient to consider couple of points of spool position, for example 1/3,2/3 and maximum opening produced by the spool displacement in the base. Afterwards, these values of the flow rate $Q$ vs position $x$ are set as boundary condition in SolidWorks Flow Simulation and Amesim.

Flow rate versus pressure. Working fluid is chosen MOBIL DTE25 at a temperature $38^{\circ} \mathrm{C}$, while tank gauge pressure is set to 0.5 bar (1.5 bar in absolute). Before conducting an experiment, pressure transducers are calibrated by using rotary dead weight tester. Experimental layout is seen in Figure 4 . Flow generated by a flow generation unit in line P and present at the inlet of PVP. The pressure transducer 3 shows its pressure. Solenoid 4 controls the position of the main spool, while the analog position sensor 1 measures position of the spool lever. Venturi flow meter HM11 2 measures flow rate through line A. There are two pressure transducer measuring pressure at port A and B (not seen in picture). By acting on the spool with the solenoid 4, presures at ports $\mathrm{P}, \mathrm{B}$ and $\mathrm{A}$ are measured. 


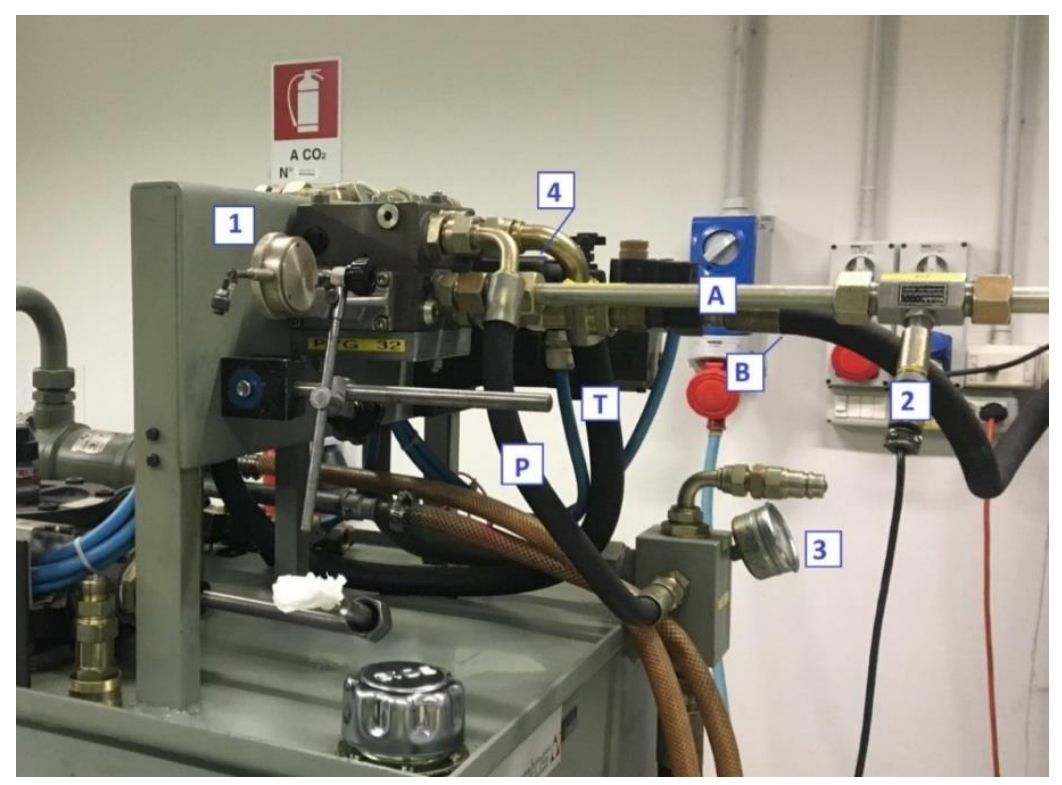

Figure 4. Experimental test layout

Figure 5 summarizes pressure flow characteristics obtained during the laboratory test.

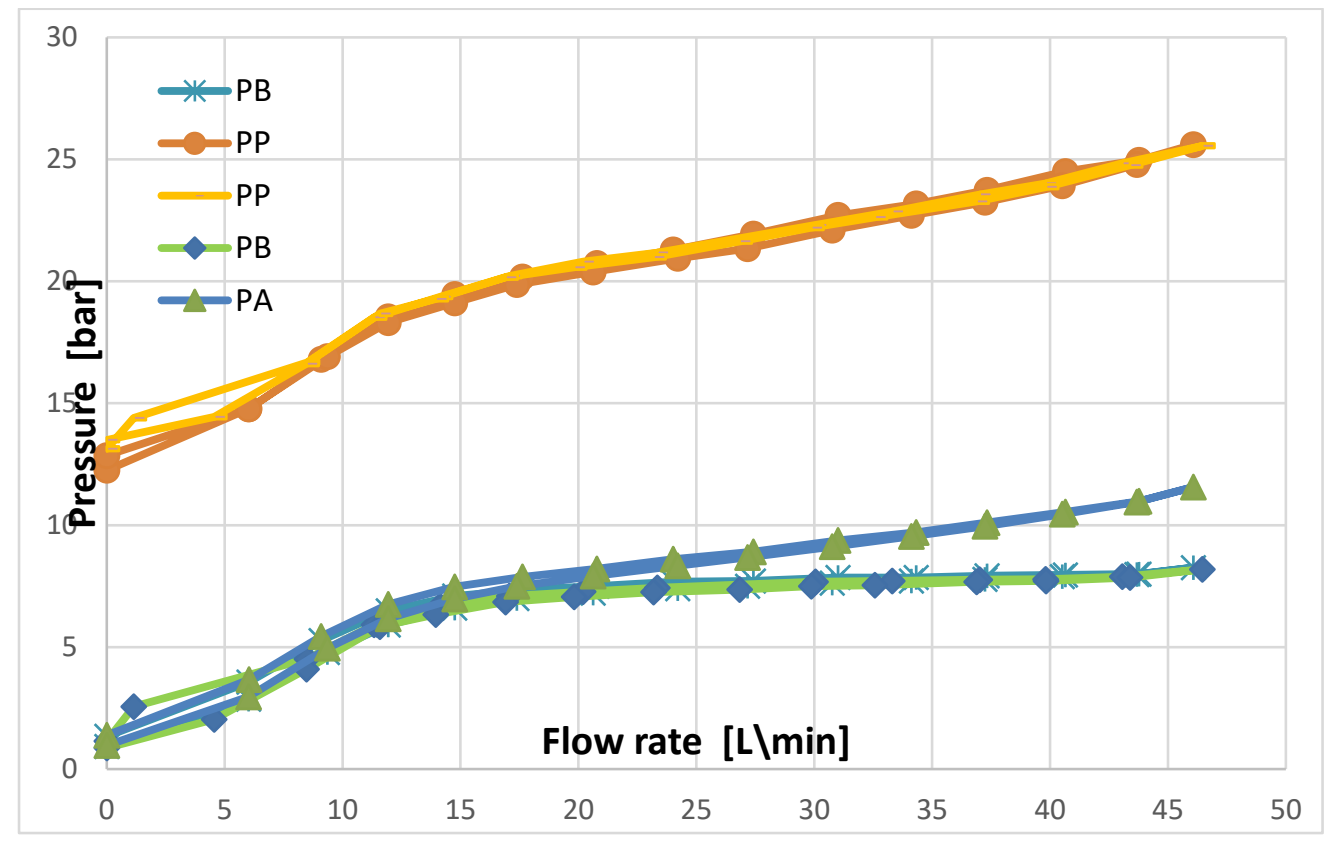

Figure 5. Experimental test values

As seen from the figure above, an upper graph shows two repititions of pressure vs flow measurements at port $\mathrm{P}$ to observe repeatability. In the lower part of the figure, graphs of pressure vs flow rate of port $\mathrm{A}$ and B (with two repititions) are seen.

\section{SoildWorks Flow Simulation}

Solidworks Flow simulation is a convenient CFD tool. As it is mentioned above, spool position and flow rate are taken as boundary conditions. As an output of CFD simulation, the pressure drop across the PVB module $\Delta \mathrm{p}$ is computed. The outlet pressure can be set to ambient atmospheric pressure. It is also necessary to consider mesh sensitivity analysis to find the minimum number of cells able to accurately represent fluid- 
dynamics. For example, one can create a graph of $\Delta \mathrm{p}$ versus number of fluid cells, and reach asymptotic value for $\Delta \mathrm{p}$ as mesh is refined.

So the first observation should be to verify wheter the pressure drop across PVG32 obtained by experiment is in line with the one generated with SolidWorks CFD. In case of positive result, by using values of $\Delta p, Q$ and $\mathrm{A}$, it is possible to compute the discharge coefficients $\mathrm{C}_{\mathrm{d}}$ at the metering edges of local compensator and the main spool by using the following well-known relationship (1).

$$
Q=C_{d} A \sqrt{\frac{2 \Delta p}{\rho}}
$$

$B-T$ connection Below is the table and graph of discharge coefficient $C_{d}$ of the metering edge connecting $B$ and $\mathrm{T}$ ports, when Amesim parameter $\mathrm{C}_{\mathrm{d}}$ is chosen so that the pressure at port $\mathrm{B}$ approaches experimental test pressure $\mathrm{pB}$.

Table 1. Amesim $\mathrm{C}_{\mathrm{d}}$ approaching lab test results

\begin{tabular}{ccccc}
\hline Xs [mm] & Q [L/min] & $\begin{array}{c}\text { Lab test } \\
\text { pB [bar] }\end{array}$ & $\begin{array}{c}\text { Amesim } \\
\text { pB [bar] }\end{array}$ & Amesim C $[-]$ \\
\hline 2,45 & 14,13 & 7,69 & 7,83 & 0,7080 \\
3,78 & 23,34 & 8,77 & 8,50 & 0,6720 \\
5,6 & 37,01 & 8,7 & 8,00 & 0,6870 \\
6,5 & 43,06 & 8,89 & 8,60 & 0,7440 \\
7 & 46,45 & 9,19 & 9,10 & 0,7590 \\
& & & Mean value: & 0,7140 \\
\hline
\end{tabular}

Below is the table and graph of discharge coefficient $C_{d}$ when Amesim parameter $C_{d}$ is chosen to approach Solidworks Flow Simulation.

Table 2. Amesim $C_{d}$ approaching Solidworks results

\begin{tabular}{ccccc}
\hline Xs [mm] & Q [L/min] & $\begin{array}{c}\text { SWFS } \\
\text { pB [bar] }\end{array}$ & $\begin{array}{c}\text { Amesim } \\
\text { pB [bar] }\end{array}$ & Amesim C $[-]$ \\
\hline 2,45 & 14,13 & 11.0 & 7.83 & 0,65 \\
3,78 & 23,34 & 10.90 & 8.2 & 0,67 \\
5,6 & 37,01 & 10.70 & 8.5 & 0,71 \\
7 & 46,45 & 11 & 10.5 & 0,72 \\
& & & Mean value: & 0,7140 \\
\hline
\end{tabular}

$P-A$ connection Below is the table and graph of discharge coefficient $\mathrm{C}_{\mathrm{d}}$ of the metering edge connecting $\mathrm{P}$ and A ports, when Amesim parameter $C_{d}$ is chosen to approach lab test values.

Table 3. Amesim Cd approaching lab test results

\begin{tabular}{ccccc}
\hline Xs [mm] & Q_P [L/min] & pA [bar] & Lab Q & Q_P [L/min] \\
\hline 2,23 & 11,93 & 6,75 & 19,55 & 19,4 \\
3,98 & 24,04 & 9,61 & 22,28 & 25,25 \\
5,76 & 37,32 & 11,11 & 24,73 & 23,81 \\
7 & 46 & 12,56 & 25,6 & 25,1 \\
& & & Mean value: & 0,70925
\end{tabular}

Below is the table and graph of discharge coefficient $\mathrm{C}_{\mathrm{d}}$ of the metering edge connecting $\mathrm{P}$ and $\mathrm{A}$ ports, when Amesim parameter $C_{d}$ is chosen to approach Solidworks values. 
Table 4. Amesim $C_{d}$ approaching Solidworks results

\begin{tabular}{cccccc}
\hline Xs [mm] & Q_P [L/min] & pA [bar] & SWFS pP[bar] & $\begin{array}{c}\text { Amesim } \\
\text { pP [bar] }\end{array}$ & Amesim Cd \\
\hline 2,23 & 11,93 & 6,75 & 23,3 & 19,4 & 0,61 \\
3,98 & 24,04 & 9,61 & 25,18 & 25,25 & 0,708 \\
5,76 & 37,32 & 11,11 & 25,26 & 23,81 & 0,66 \\
7 & 46 & 12,56 & 24,22 & 25,1 & 0,725 \\
& & & & Mean value: & 0,67575 \\
\hline
\end{tabular}

In summary, it is seen that discharge coefficients at the P-A and B-T connections fluctuates around 0.7. Regarding $\mathrm{C}_{\mathrm{d}}$ at local compensator, CFD simulation demonstrated insignificant pressure drop across LC. Therefore, it is possible to set $\boldsymbol{C}_{\boldsymbol{d}}=\mathbf{0 . 7}$ at the metering edges of the mathematical model of PVB module.

\section{Amesim modeling}

Below is the mathematical model of the PVB. It is composed two components, namely, the local pressure compensator on the left and the main spool on the right. Ports A and B are interconnected via restrictor. As input parameters, position of the spool and pressure is given. As an output, flow rate through the valve is computed. As the experimental simulation is performed with fixed LC, mass component of the local compensator model has upper displacement limit.

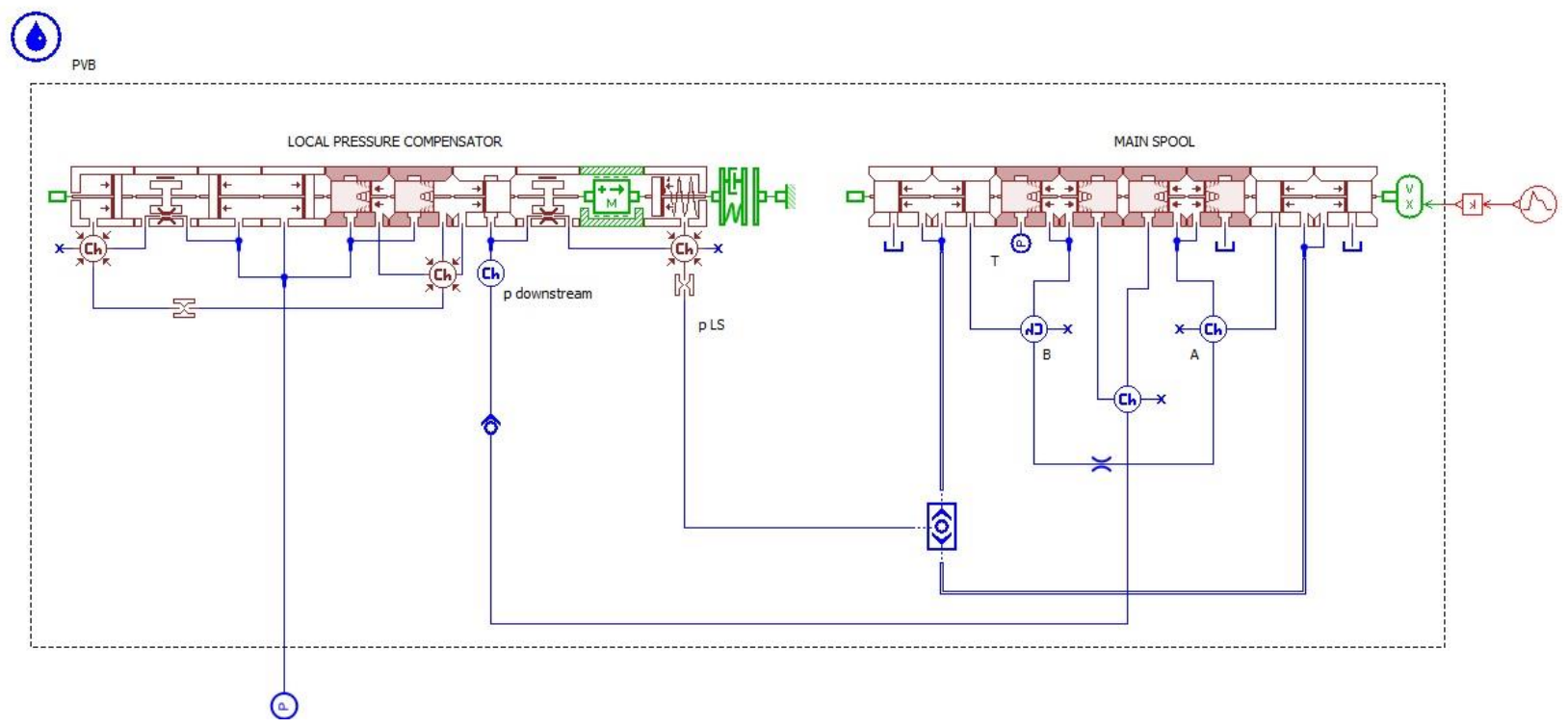

Figure 6. Amesim model of PVB

Below is the table of flow rates in experimental test and Amesim simulation. The first two columns are the input to Amesim model: position of the spool and the inlet pressure. The final column is the flow rate produced by the Amesim model. As seen in the table and bar chart below, the Amesim model demonstrates accurate results of flow rate with respect to experimental test. 


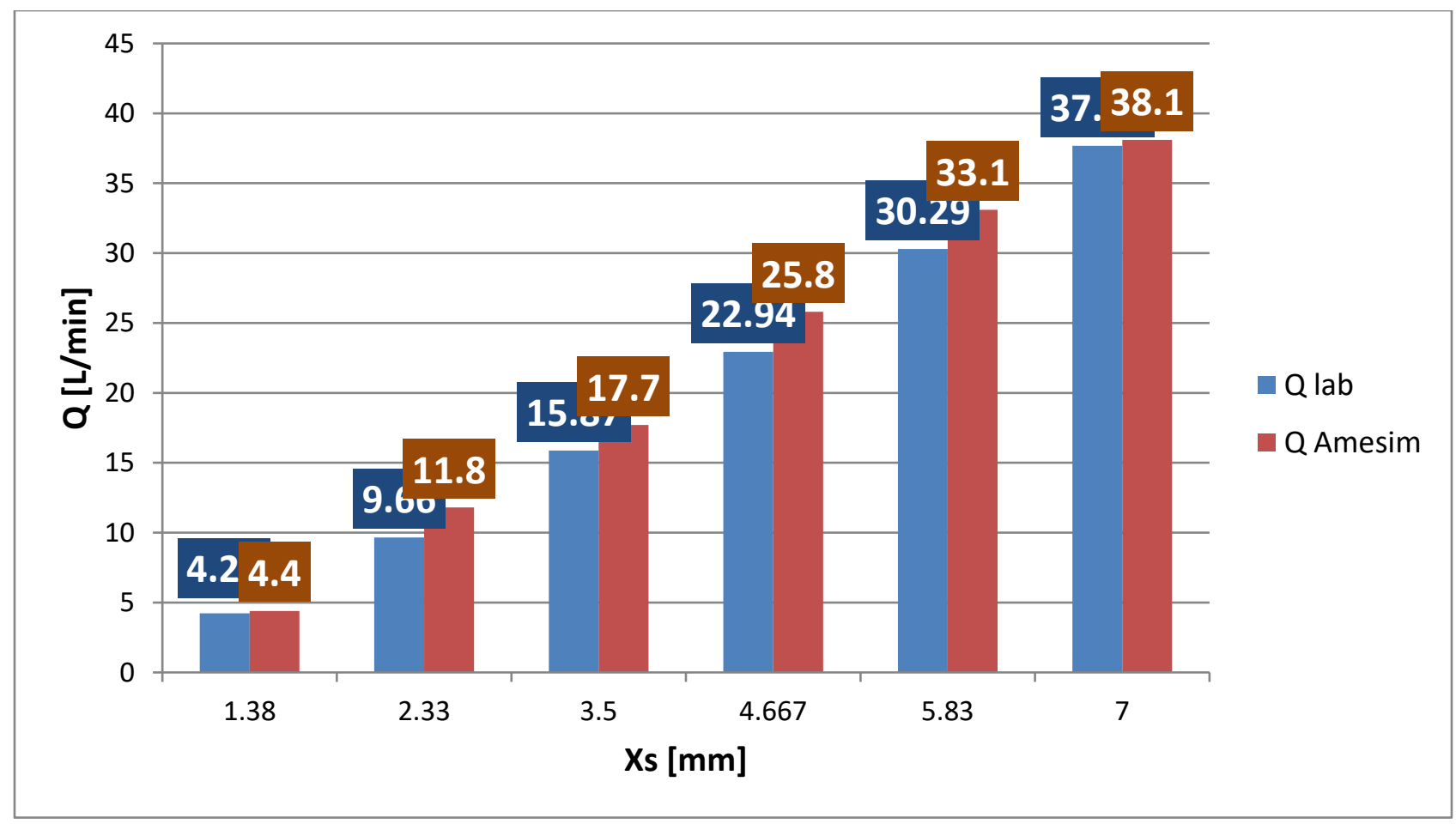

Figure 7. Flow rate vs. spool displacement with LC locked at $3.2 \mathrm{~mm}$

Now it is possible to pose a question: what happens if LC is free to regulate? In other words, can the Amesim model of the PVB suitably replicate the experimental test results when LC has no upper displacement limit? The answer lies in the most important part of the main spool, i.e. the notch connecting power port with the working port. Therefore with great attention, flow area versus displacement data should be calculated for the notch connecting working port, 3D of which is given below.
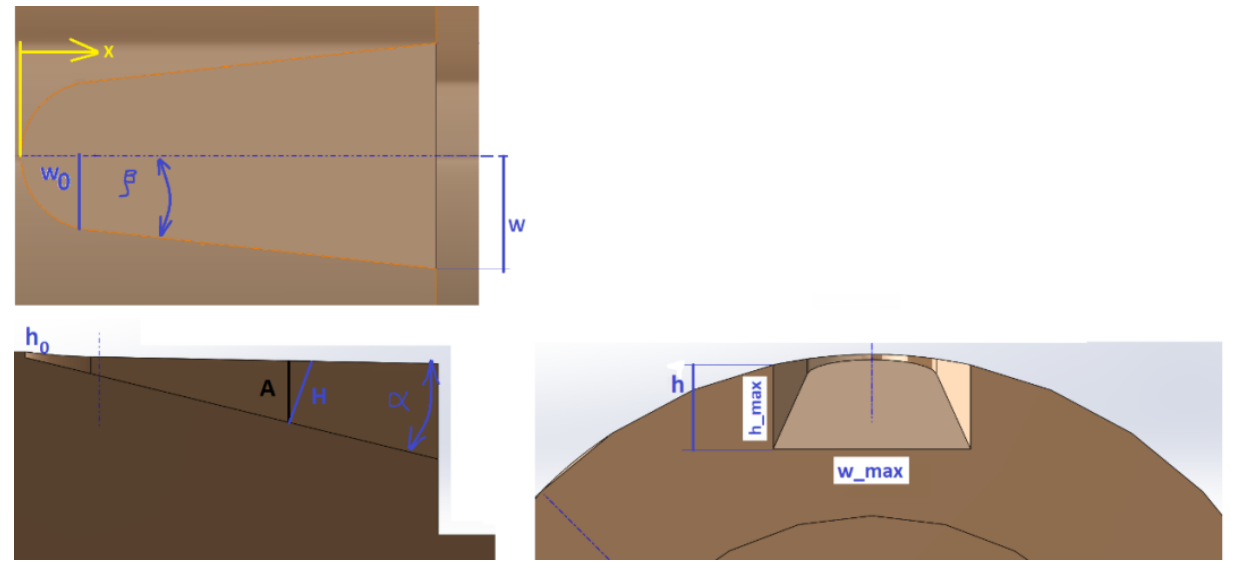

Figure 8. Notch and some useful nomenclature used for analytical calculation of the flow area versus displacement

Orthogonal area has the shape of rectangle. From 3D drawing as above, it is possible to obtain the following information:

$$
\alpha=13.4^{\circ} \text { and } h_{0}=0.29 \mathrm{~mm} ; \quad w_{0}=1.27 \mathrm{~mm} \text { and } \beta=6.37^{\circ} \text {; }
$$

$A$ is the plane perpendicular to spool axis and $A=A_{1}+A_{2}$, where $A_{1}$ is the area of the rectangle of width $2 w$ and $h$; and $A_{2}$ is the area of the segment between arc and rectangle. Let us assume that the latter $A_{2}$ is negligible.

The area of the rectangle is then 


$$
A=A_{1}=2 w \times h
$$

$\mathrm{H}=\frac{A}{\cos \alpha}$ is a plane normal to the notch skew plane.

Let $h_{1}$ be the height of the rectangle at displacement $x$. Then $h_{1}=\tan \alpha \times x$. Analogously, we relate $w$ with spool position $x$.

$h=h_{0}+h_{1}=h_{0}+\tan \alpha \times x ; \quad w=w_{0}+w_{1}=w_{0}+\tan \beta \times x$

Frontal area (aka radial) is the sum of the trapezoid $F_{2}$ and a half circle $F_{1}$.

$$
F=F_{1}+\frac{2\left(w+w_{0}\right)}{2} \times x
$$

$F_{1}$ is calculated with reference to [3].

Finally, by choosing minimum between frontal and orthogonal areas and minimum is imposed to Amesim.

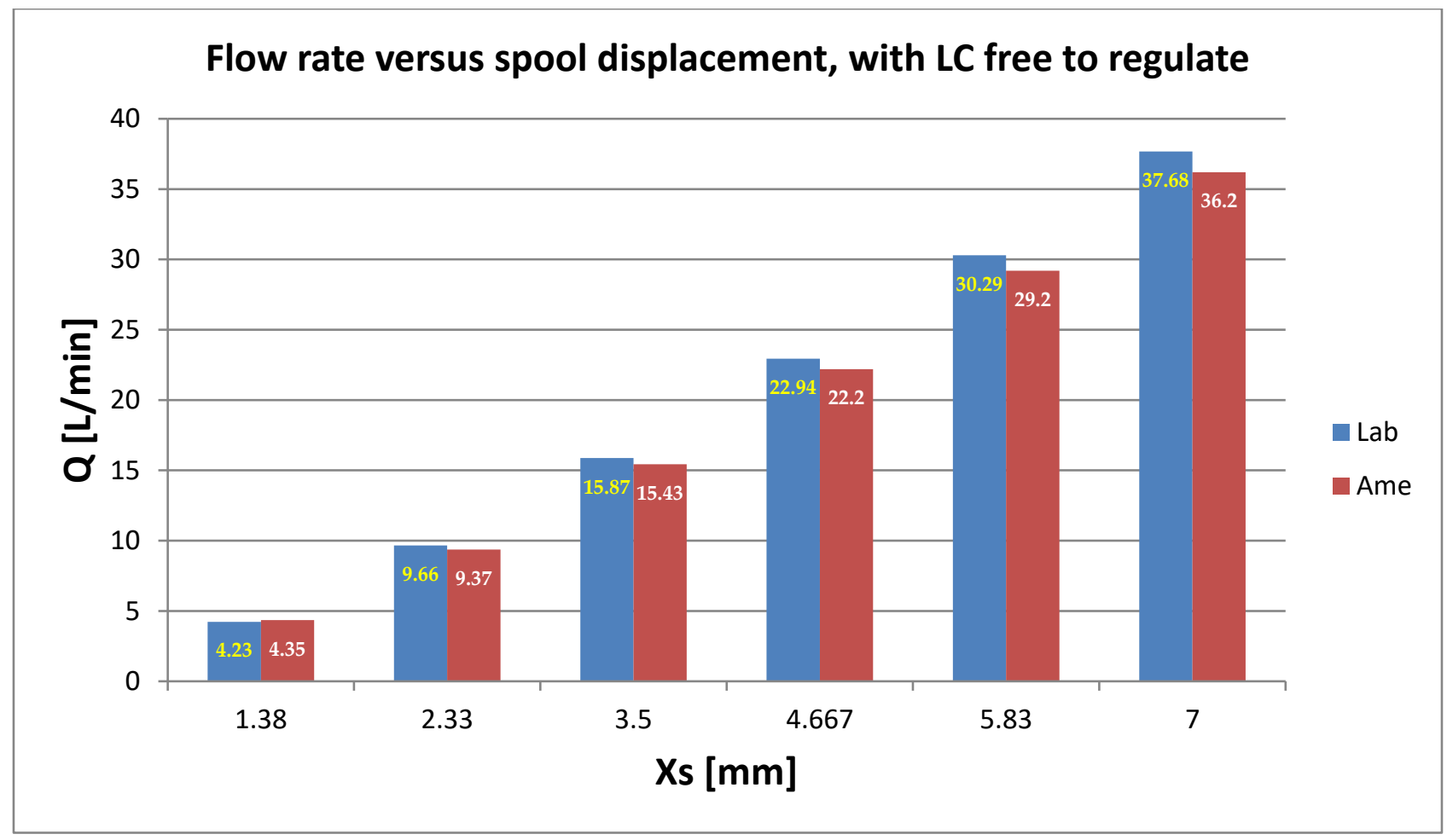

Figure 9. Flow rate versus spool displacement with LC free to regulate

\section{Conclusions}

The hydraulic proportional load sensing valve PVB was discussed through the simulation and experimental analysis. These useful conclusions are obtained:

(1) The mathematical model made in Amesim of the PVB module of the PVG32 block correctly describes the real valve.

(2) Considerable throttling losses are observed at the connection between $\mathrm{B}$ and $\mathrm{T}$ when connection $\mathrm{P}$ and $\mathrm{A}$ is open, since the spool valves are designed with over-running loads in mind.

(3) Further research will concentrate on energy saving techniques by using independent metering, electronic flow matching, etc.

Acknowledgments: All material relative to experimental tests (circuit data and measurements) has been kindly provided by the Fluid Power Research Laboratory of the Politecnico di Torino. The author acknowledges permission of publishing 
the present material. Author would like to thank Dr. Giorgio Altare for the revision of the 3D CAD model of the PVG module and Prof. Massimo Rundo for the revision of the Amesim and Solidworks models.

Author Contributions: Sanjar Mirzaliev wrote the paper. Kongratbai Sharipov reviewed the experiments and analyzed the data.

Conflicts of Interest: The authors declare no conflict of interest.

Nomenclatures and Symbols

$Q$ is the flow rate. A is the throttling area, while $\mathrm{C}_{\mathrm{d}}$ is the discharge coefficient. $\Delta p$ is the pressure drop. $\rho$ is the density of working fluid. P,A/B, T are ports of the valve. Pressure margin is $s$.

\section{References}

1 Technical Information. PVG 32. Proportional Valve Group. http://files.danfoss.com/documents/52010344.pdf

2 Simulation of a load sensing forklift truck, Master thesis, Sanjar Mirzaliev.

3 Nervegna, N., Rundo, M.: Fluid power 2, Politeko, 2012, ISBN 978-88-97862-00-0.

4 Savarino, F.: Analisi preliminare di un distributore Load Sensing (Preliminary analysis of a load sensing direction control valve), Bachelor Thesis, Politecnico di Torino, 2007 (In Italian)

5 Rabie, M. Galal. Fluid power engineering. Vol. 28. New York, NY, USA: McGraw-Hill, 2009 